\title{
Tradução e adaptação transcultural do Interdisciplinary Medicine Instrument (INTERMED): método de avaliação biopsicossocial no Brasil
}

\section{Bernardete Weber}

Doutorado pela Escola de Enfermagem da Universidade de São Paulo (EE-USP); Mestrado em Educação pela Pontifícia Universidade Católica do Rio Grande do Sul (PUCRS); Especialização em Administração Hospitalar pela Associação dos Hospitais do Estado do Rio Grande do Sul; Graduação em Nutrição pela Universidade do Vale do Rio dos Sinos (UNISINOS). bweber@hcor.com.br

\section{Flávia Renata Fratezi}

Graduação em Gerontologia pela Escola de Artes, Ciências e Humanidades da Universidade de São Paulo (EACH-USP). flaviafratezi@gmail.com

\section{Érica Aranha Suzumura}

Especialização em Fisioterapia Cardiovascular Funcional pelo Instituto Dante Pazzanese de Cardiologia; Graduação em Fisioterapia pela Universidade Estadual de Londrina.esuzumura@yahoo.com.br

\section{Beatriz Aparecida Ozello Gutierrez}

Doutorado pela Escola de Enfermagem da Universidade de São Paulo (EE-USP); Mestrado pela EEUSP; Especialização em Administração de Serviços de Saúde pela Sociedade Brasileira de Enfermeiros em Terapia Intensiva; Graduação em Enfermagem pela EE-USP.

\section{Armando Antonio De Negri Filho}

Mestrado em Ciências - Epidemiologia pela Universidade Federal de Pelotas; Graduação em medicina pela Universidade Federal do Rio Grande do Sul (UFRGS). armandodenegri@yahoo.com

\author{
Maria Helena Trench Ciampone \\ Livre docência pela Escola de Enfermagem da Universidade de São Paulo (EE-USP); Doutorado \\ pelo Instituto de Psicologia da Universidade de São Paulo; Mestrado pela EE-USP; Graduação em \\ Enfermagem pela EE-USP. mhciamp@usp.br
}

\begin{abstract}
RESUMO: Objetivo: realizar adaptação transcultural e tradução do método INTERMED para uso no Brasil. Métodos: estudo transversal. INTERMED é um sistema para classificar complexidade biopsicossocial de pacientes em diversos níveis de assistência, identificar suas necessidades e melhorar a comunicação interprofissional. Composto de 20 variáveis relacionadas aos domínios biológico, psicológico, social e sistema de saúde, em uma perspectiva temporal de história, estado atual e prognóstico. A adaptação transcultural compreendeu cinco fases: tradução; síntese; retrotradução; avaliação por especialistas; e pré-teste. Resultados: na tradução do INTERMED do inglês para o português houve pequenas diferenças entre duas traduções independentes, resolvidas por consenso entre seis pesquisadores, resultando na versão síntese. A equivalência entre o instrumento traduzido e o original foi verificada por um comitê de juízes, composto por nove profissionais. No pré-teste obteve-se percentual de compreensão, pelos pacientes, acima de $90 \%$ em todos os itens do instrumento. Conclusão: o INTERMED está adequadamente traduzido e adaptado para a realidade brasileira.
\end{abstract}

PALAVRAS-CHAVE: Tradução; Gestão em saúde; Cuidados integrais de saúde.

\section{Translation and cultural adaptation of the Interdisciplinary Medicine Instrument (INTERMED): method of biopsychosocial assessment in Brazil}

ABSTRACT: Objective: To perform the translation and cross-cultural adaptation of the INTERMED method for use in Brazil. Methods: It was a cross-sectional study. The INTERMED method is a system to classify the biopsychosocial complexity of patients in different levels of care, to identify their needs and to improve interprofessional communication. This method has 20 variables related to biological, psychological, social and health care domain in the context of time (history, current state, and prognosis). The adaptation process followed five steps: translation to Brazilian Portuguese, synthesis, back translation to English, expert committee's evaluation, and pretest of the final version of INTERMED method in Portuguese. Results: In the INTERMED translation from English to Portuguese there were few differences between two independent translations, which were resolved by consensus of six researchers, resulting in the synthesis version. The assessment of equivalence between the original and the translated instrument was checked by an expert committee, composed by nine professionals. The pretest obtained an understanding percentage over $90 \%$ on all items of the instrument. Conclusion: The INTERMED method is adequately translated to Portuguese and adapted to the context of Brazilian health.

KEY WORDS: Translation; Health management; Integrated healthcare.

* Submetido em 28 de Novembro de 2012. Aceito em 20 de Dezembro de 2012. O artigo foi avaliado segundo o processo de duplo anonimato além de ser avaliado pelo editor. Editores responsáveis: Márcio Augusto Gonçalves e Lucas Maia dos Santos. Reprodução parcial ou total de trabalhos derivativos permitidos com a citação apropriada da fonte. 


\section{INTRODUÇÃO}

O modelo de saúde biomédico, ainda predominante nas práticas assistenciais, nem sempre considera as dimensões psicológica, social e comportamental do indivíduo. Para compreender os determinantes do processo saúde-doença e chegar a tratamentos racionais e padrões de cuidado à saúde, é necessário um modelo assistencial no qual se considere o paciente, o contexto social em que vive, o sistema complementar e as redes de apoio social existentes, ou seja, um modelo de atenção integral que considere a dimensão biopsicossocial.

Nesse sentido, um grupo de pesquisadores holandeses desenvolveu um método, denominado INTERMED, para operacionalizar e integrar sistematicamente os aspectos biológico, psicológico e social do indivíduo, estabelecendo sua relação com o sistema de saúde, de modo a possibilitar o ajustamento mútuo entre as ações dos profissionais de saúde envolvidos, de acordo com o nível de necessidades do paciente, vislumbrando a integralidade do cuidado.

O método INTERMED corresponde a um instrumento que complementa a tradicional entrevista médica e, como qualquer outro documento, pode ser acrescentado ao prontuário médico, constituindo-se em ferramenta para apoiar decisões e gerenciamento de casos. Estudos prévios demonstraram que o método INTERMED é confiável para classificar o cuidado dos pacientes, segundo as suas necessidades de saúde em geral e de saúde mental. O método já foi traduzido para diferentes idiomas, como inglês, alemão, francês, espanhol, italiano, japonês e norueguês (INTERMED FOUNDATION, 2010; disponível em www.intermedfoundation.org).

O presente estudo teve como objetivos realizar a tradução e a adaptação transcultural do método INTERMED para o idioma português falado no Brasil.

\section{MÉTODOS}

Este estudo foi do tipo transversal para tradução e adaptação transcultural do método INTERMED. Composto de 20 variáveis, o método sintetiza informações relacionadas a quatro domínios: biológico, psicológico, social e sistema de saúde, em uma perspectiva do tempo que consiste na história, estado atual e prognóstico, conforme resumido no Quadro 1.

QUADRO 1. Domínios e variáveis do INTERMED (São Paulo, 2012).

\begin{tabular}{llll}
\multicolumn{1}{c}{ Domínios } & \multicolumn{1}{c}{ História } & \multicolumn{1}{c}{ Estado atual } & \multicolumn{1}{c}{ Prognóstico } \\
Biológico & $\begin{array}{l}\text { Cronicidade } \\
\text { Dilema diagnóstico }\end{array}$ & $\begin{array}{l}\text { Gravidade dos sintomas } \\
\text { Desafio diagnóstico/terapêutico }\end{array}$ & $\begin{array}{l}\text { Complicações/ameaça à } \\
\text { vida }\end{array}$ \\
\cline { 1 - 3 } Psicológico & $\begin{array}{l}\text { Barreiras de enfrentamento } \\
\text { Disfunção psiquiátrica }\end{array}$ & $\begin{array}{l}\text { Resistência ao tratamento } \\
\text { Sintomas psiquiátricos }\end{array}$ & Ameaça à saúde mental \\
Social & $\begin{array}{l}\text { Problemas no trabalho e lazer } \\
\text { Condições no domicílio } \\
\text { Situação social }\end{array}$ & Rede de apoio social & Vulnerabilidade social \\
Saúde & Acesso ao cuidado & $\begin{array}{l}\text { Organização do cuidado } \\
\text { Coordenação do cuidado }\end{array}$ & $\begin{array}{l}\text { Impedimentos do sistema/ } \\
\text { plano de saúde }\end{array}$ \\
\hline
\end{tabular}

Fonte: Adaptado de Huyse et al. (1999).

Conforme sintetizado no Quadro 2, o instrumento é organizado em 12 células. Os escores para cada variável dos domínios do INTERMED são representados em uma escala do tipo Likert, cuja pontuação foi definida como:

0 - nenhuma vulnerabilidade/necessidade;

1 - pouca vulnerabilidade/necessidade de monitoramento ou prevenção;

2 - vulnerabilidade moderada/necessidade de tratamento ou inclusão em um plano de tratamento;

3 - vulnerabilidade intensa/necessidade imediata de intervenção ou tratamento intensivo.

A pontuação pode variar de zero a 60 pontos, sinalizando a vulnerabilidade ou a necessidade de cada paciente, de acordo com a seguinte classificação: < 21 pontos: paciente não complexo; entre 21 e 30 pontos: complexidade limítrofe; e $>30$ pontos: paciente complexo, que necessita de gerenciamento de caso e cuidado interprofissional. 
QUADRO 2. Informações coletadas nos domínios do Intermed (São Paulo, 2012).

\begin{tabular}{|c|c|}
\hline História & Informação coletada \\
\hline Biológico & Cronicidade de uma dada doença e episódios anteriores de diagnósticos incertos. \\
\hline Psicológico & Estratégias de enfrentamento e histórico psiquiátrico \\
\hline Social & $\begin{array}{l}\text { Integração social, em termos de emprego e atividades de lazer e a capacidade do paciente } \\
\text { em manter relações sociais. }\end{array}$ \\
\hline Sistema de saúde & Intensidade e adequação dos cuidados requeridos anteriormente. \\
\hline \multicolumn{2}{|l|}{ Estado atual } \\
\hline Biológico & Gravidade dos sintomas, relatos de perdas físicas e complexidade de diagnósticos \\
\hline Psicológico & Nível de cooperação do paciente ao tratamento \\
\hline Social & Situações atuais vividas e relações de suporte social, como família, amigos ou colegas \\
\hline Sistema de saúde & $\begin{array}{l}\text { Complexidade organizacional em termos de números e tipos de condições do cuidado à } \\
\text { saúde, antes e depois de uma doença }\end{array}$ \\
\hline \multicolumn{2}{|l|}{ Prognóstico } \\
\hline Biológico & $\begin{array}{l}\text { Resultados esperados da doença, como deficiências, complicações ou recorrência da doença } \\
\text { ou ameaça à vida }\end{array}$ \\
\hline Psicológico & $\begin{array}{l}\text { Declínio mental esperado e necessidades psicológicas que podem resultar de doenças } \\
\text { atuais ou antecedentes psiquiátricos }\end{array}$ \\
\hline Social & Necessidades sociais esperadas a respeito da integração social do paciente \\
\hline Sistema de saúde & $\begin{array}{l}\text { Cuidados à saúde que são esperados em termos de intensidade e de complexidade da } \\
\text { organização do sistema }\end{array}$ \\
\hline
\end{tabular}

\subsection{Tradução e adaptação transcultural}

O processo de adaptação transcultural adotado neste estudo compreendeu cinco fases: tradução, síntese, retrotradução, avaliação por um grupo de especialistas e pré-teste.

O instrumento original foi traduzido por dois tradutores independentes, brasileiros e com bom domínio do inglês, sendo uma enfermeira com conhecimento dos objetivos do estudo e uma professora de inglês, sem conhecimento prévio da pesquisa.

Com base nessas traduções e no instrumento original, foi composta uma versão-síntese, obtida por consenso entre um grupo de seis pesquisadores com formação em Nutrição, Enfermagem, Fisioterapia e Gerontologia. Essa versão foi retrotraduzida por dois tradutores independentes que não conheciam o instrumento original. Um profissional era americano e o outro inglês, ambos com bom domínio do idioma português e um deles com experiência em ensino de inglês para profissionais da área da saúde.

Em seguida, um comitê de juízes, composto por nove profissionais com experiência em gestão em saúde, assistência e metodologia de pesquisa, avaliou a equivalência entre o instrumento traduzido e o original. A seleção dos juízes foi baseada nos seguintes critérios: ser profissional da área de saúde; ter domínio da língua inglesa; conhecer os processos de construção e adaptação de instrumentos; conhecer a temática do cuidado integral; e ter experiência assistencial com pacientes clínico-cirúrgicos. Os dois primeiros critérios foram considerados imprescindíveis, sendo necessário que os juízes apresentassem, pelo menos, mais um dos demais critérios.

Os membros do comitê receberam todas as versões do instrumento: o original, as duas traduções, a síntese das traduções e as duas retrotraduções, bem como um formulário de instruções para avaliação das equivalências, no qual deveriam assinalar a opção 1 para não equivalente, 0 para indeciso e 1 para equivalente.

A equivalência foi verificada pelos juízes em três áreas: semântica, idiomática e cultural, que se referem, respectivamente, à equivalência no significado das palavras, envolvendo o vocabulário e a gramática; à correspondência de expressões idiomáticas e coloquiais; e às situações evocadas ou retratadas nos itens que deveriam corresponder às vivências no contexto cultural brasileiro.

Após estudo individual das versões, os juízes enviaram suas contribuições, que foram avaliadas e compiladas pelos pesquisadores. A concordância entre os especialistas foi avaliada por meio do índice de validade de conteúdo (IVC), calculado como a razão entre o número de itens avaliados como equivalentes por dois juízes e o total de itens da escala. 
Posteriormente, os especialistas reuniram-se na conferência de consenso para alcançar a equivalência entre o instrumento original e a versão final a ser testada. Na reunião, foram apresentadas aos juízes todas as contribuições enviadas e, por consenso, ao final da reunião do comitê, o grupo consolidou todas as versões do instrumento, compondo a versão pré-final.

No mês de setembro de 2011, a versão pré-final foi aplicada a uma amostra de 30 indivíduos, conforme recomendações prévias, em três instituições hospitalares com diferentes perfis de população: uma privada, uma de ensino e uma pública. Foram incluídos pacientes com idade igual ou superior a 21 anos e tempo de internação de cinco ou mais dias por doenças clínico-cirúrgicas. O entrevistador identificava no censo diário os pacientes potencialmente elegíveis para a pesquisa e, em seguida, reunia-se com integrantes da equipe assistencial da unidade para confirmar a elegibilidade. Posteriormente, seguia-se a análise do prontuário e, finalmente, o contato com o paciente. Antes da aplicação do pré-teste, o pesquisador explicava os objetivos do estudo e solicitava a participação do paciente por meio da assinatura no Termo de Consentimento Livre e Esclarecido.

Nessa fase, cada participante relatou seu entendimento sobre os itens do INTERMED e respectivas respostas, suas dúvidas e sugestões de reformulação para melhor entendimento, a fim de assegurar que a versão traduzida do instrumento mantivesse sua equivalência com o original, em sua aplicação.

Além das cinco fases descritas, foi composto um grupo focal com a participação de 12 enfermeiros, dois gerontólogos, um fisioterapeuta, um psicólogo, um nutricionista e um psiquiatra, todos com experiência em pesquisa e/ou assistência. A coordenação do grupo foi atribuída a uma médica psiquiatra brasileira, que acumula ampla experiência na utilização do método em uma universidade canadense, no âmbito do ensino, pesquisa e assistência, utilizando o INTERMED na sua prática clínica, Essa pesquisadora foi indicada pela equipe da INTERMED Foundation, de Amsterdan, Holanda, que idealizou e desenvolveu o método.

O grupo focal objetivou a discussão inicial sobre a equivalência cultural do instrumento traduzido. Sob a coordenação da pesquisadora indicada, seguiu-se a criteriosa leitura do método INTERMED, com sugestões dos presentes para melhor adequação cultural do instrumento. No grupo, todos os participantes puderam expressar suas opiniões e enriquecer as discussões, devido às diferentes experiências profissionais, permitindo, assim, criteriosa avaliação do INTERMED e das hipóteses do estudo, favorecendo a apropriação do método pelos membros do grupo e melhor desenvolvimento da pesquisa.

Quanto às questões éticas, foi solicitada autorização da INTERMED Foundation para utilização do método INTERMED neste estudo. A pesquisa foi conduzida em conformidade com a Declaração de Helsinque e a Resolução n. 196/96 e complementares do CNS/MS e foi aprovada pelos Comitês de Ética em Pesquisa de todas as instituições participantes.

\section{RESULTADOS}

Na tradução do INTERMED do inglês para o português houve pequenas diferenças entre as duas traduções, as quais foram resolvidas por consenso pelo grupo de pesquisadores para gerar a versão síntese. O Quadro 3 ilustra as principais diferenças entre as duas traduções e como foram resolvidas.

As retrotraduções foram avaliadas pelo grupo de pesquisadores, que concluiu não haver diferenças significativas entre as duas retrotraduções e o instrumento original. As versões retrotraduzidas foram validadas pela pesquisadora consultora indicada pela equipe que desenvolveu o instrumento original. Dessa forma, originou-se a primeira versão traduzida do método INTERMED, que foi submetida ao comitê de juízes.

A avaliação das equivalências semântica, idiomática e cultural foi verificada pelo comitê de juízes, composto por nove profissionais, sendo dois psicólogos, um médico clínico, um psiquiatra, um epidemiologista, três enfermeiros e um assistente social.

Dos nove juízes participantes, todos devolveram o material de avaliação com suas sugestões, no entanto, três deles não assinalaram a nota correspondente à equivalência.

Os valores obtidos com a avaliação da concordância entre juízes, por meio do IVC, estão apresentados na Tabela 1, em que a intersecção de cada linha e coluna representa a porcentagem de respostas equivalentes entre cada um dos pares de juízes. Os mais baixos índices de concordância foram observados no aspecto cultural, em que o valor mínimo de IVC foi 0,7 , considerado satisfatório para avaliação de concordância. 
QUADRO 3. Principais diferenças entre as duas traduções do Intermed (São Paulo, 2012).

\begin{tabular}{|c|c|c|c|}
\hline Original & Tradução 1 & Tradução 2 & Consenso \\
\hline $\begin{array}{l}\text { Symptom Severity/ } \\
\text { Impairment }\end{array}$ & $\begin{array}{l}\text { Gravidade/Insuficiência dos } \\
\text { sintomas }\end{array}$ & $\begin{array}{l}\text { Gravidade dos sintomas/ } \\
\text { Comprometimento }\end{array}$ & $\begin{array}{l}\text { Gravidade dos Sintomas/ } \\
\text { Comprometimento }\end{array}$ \\
\hline $\begin{array}{l}\text { Mild but notable } \\
\text { symptoms }\end{array}$ & $\begin{array}{l}\text { Sintomas leves, mas } \\
\text { notáveis }\end{array}$ & $\begin{array}{l}\text { Sintomas leves, mas } \\
\text { significativos }\end{array}$ & $\begin{array}{l}\text { Sintomas leves, mas } \\
\text { significativos }\end{array}$ \\
\hline Severe & Graves & Severos & Graves \\
\hline Inability & Inabilidade & Incapacidade & Incapacidade \\
\hline No & Sem & Nenhum & Nenhum \\
\hline Substantial & Substanciais & Significativas & Significativas \\
\hline Illness & Enfermidade & Doença & Doença \\
\hline Medical & Médica & Clínica & Clínica \\
\hline Admission & Admissão & Hospitalização & Hospitalização \\
\hline Problems & Problemas & Dificuldade & Dificuldade \\
\hline Cognitive impairment & Insuficiência cognitiva & $\begin{array}{l}\text { Comprometimento } \\
\text { cognitivo }\end{array}$ & $\begin{array}{l}\text { Comprometimento } \\
\text { cognitivo }\end{array}$ \\
\hline Disturbances & Perturbações & Distúrbios & Distúrbios \\
\hline Now & Agora & Atualmente & Atualmente \\
\hline For & Por & Durante & Durante \\
\hline Disruptive social relations & Relações sociais rompentes & $\begin{array}{l}\text { Relações sociais } \\
\text { tumultuadas }\end{array}$ & $\begin{array}{l}\text { Relações sociais } \\
\text { tumultuadas }\end{array}$ \\
\hline Residential Instability & Instabilidade de residência & Instabilidade residencial & Instabilidade residencial \\
\hline Institutional setting & Assentamento institucional & Instituição & Instituição \\
\hline But possible delays & Com atrasos & Com possíveis demoras & Com possíveis demoras \\
\hline Increased integration & Integração aumentada & Mais integração & Mais integração \\
\hline Trouble keeping consistent & Em manter consistência & $\begin{array}{l}\text { Em manter profissional es- } \\
\text { tável e/ou de preferência }\end{array}$ & $\begin{array}{l}\text { Em manter profissional } \\
\text { estável e/ou de prefe- } \\
\text { rência }\end{array}$ \\
\hline Primary ER & Pronto socorro primário & Serviço de emergência & Serviço de emergência \\
\hline Provider communication & $\begin{array}{l}\text { Comunicação com o } \\
\text { prestador }\end{array}$ & $\begin{array}{l}\text { Comunicação com os } \\
\text { profissionais }\end{array}$ & $\begin{array}{l}\text { Comunicação com os } \\
\text { profissionais }\end{array}$ \\
\hline Referral/admission & Referência/admissão & $\begin{array}{l}\text { Encaminhamento/ } \\
\text { admissão }\end{array}$ & $\begin{array}{l}\text { Encaminhamento/ } \\
\text { admissão }\end{array}$ \\
\hline Resolved & Resolvidas & Solucionadas & Solucionadas \\
\hline $\begin{array}{l}\text { Are currently diagnostic } \\
\text { investigations in process } \\
\text { for these complaints? }\end{array}$ & $\begin{array}{l}\text { Investigações diagnósticas } \\
\text { atuais estão em processo } \\
\text { para essas queixas? }\end{array}$ & $\begin{array}{l}\text { Atualmente, essas queixas } \\
\text { estão sendo investigadas? }\end{array}$ & $\begin{array}{l}\text { Atualmente, essas } \\
\text { queixas estão sendo } \\
\text { investigadas? }\end{array}$ \\
\hline Caretaker & Cuidadores & Profissionais & Profissionais \\
\hline Is there communication & Há comunicação & Existe comunicação & Existe comunicação \\
\hline You are well insured & Você está bem assegurado & $\begin{array}{l}\text { Você tem um bom seguro- } \\
\text { saúde }\end{array}$ & $\begin{array}{l}\text { Você tem um bom seguro- } \\
\text { saúde }\end{array}$ \\
\hline As far as I can see & Até onde eu posso ver & $\begin{array}{l}\text { Até onde é de meu } \\
\text { conhecimento }\end{array}$ & $\begin{array}{l}\text { Até onde é de meu } \\
\text { conhecimento }\end{array}$ \\
\hline Cultural background & Experiência cultural & Formação cultural & Formação cultural \\
\hline $\begin{array}{l}\text { Are there communicatio- } \\
\text { nal problems due to impe- } \\
\text { ded understanding of your } \\
\text { language? }\end{array}$ & $\begin{array}{l}\text { Há problemas de comunica- } \\
\text { ção devido a entendimento } \\
\text { impedido de sua linguagem? }\end{array}$ & $\begin{array}{l}\text { Há problemas de } \\
\text { comunicação devido a } \\
\text { problemas de linguagem? }\end{array}$ & $\begin{array}{l}\text { Há problemas de } \\
\text { comunicação devido a } \\
\text { problemas de linguagem? }\end{array}$ \\
\hline Job & Emprego & Trabalho & Trabalho \\
\hline Is able to leisure & É capaz de ter lazer & Consegue ter lazer & Consegue ter lazer \\
\hline $\begin{array}{l}\text { Can get along well with } \\
\text { other persons }\end{array}$ & $\begin{array}{l}\text { Consegue viver bem com } \\
\text { outras pessoas }\end{array}$ & $\begin{array}{l}\text { Consegue ter um bom } \\
\text { relacionamento com } \\
\text { outras pessoas }\end{array}$ & $\begin{array}{l}\text { Consegue ter um bom } \\
\text { relacionamento com } \\
\text { outras pessoas }\end{array}$ \\
\hline To become talkative & Tornar-se falador & Falar demais & Falar demais \\
\hline Or silent & Ficar quieto & Ficar em silêncio & Ficar em silêncio \\
\hline What doctors say & O que os médicos dizem & $\begin{array}{l}\text { que os médicos } \\
\text { recomendam }\end{array}$ & $\begin{array}{l}\text { que os médicos } \\
\text { recomendam }\end{array}$ \\
\hline
\end{tabular}


Tabela 1. Medidas de concordância entre os juízes (São Paulo, 2012).

\begin{tabular}{c|cccccc|cccccc|cccccc}
\hline & \multicolumn{1}{c}{ Semântica } & \multicolumn{1}{c}{ Idiomática } & \multicolumn{1}{c}{ Cultural } \\
\hline Juiz & 1 & 2 & 4 & 5 & 6 & 9 & 1 & 2 & 4 & 5 & 6 & 9 & 1 & 2 & 4 & 5 & 6 & 9 \\
\hline 1 & $*$ & 0,9 & 0,9 & 1,0 & 0,8 & 1,0 & $*$ & 0,9 & 0,9 & 0,9 & 0,8 & 0,9 & $*$ & 0,8 & 0,7 & 0,7 & 0,7 & 0,7 \\
2 & & $*$ & 0,9 & 0,9 & 0,8 & 0,9 & & $*$ & 0,9 & 0,9 & 0,8 & 0,9 & & $*$ & 0,7 & 0,7 & 0,7 & 0,7 \\
4 & & & $*$ & 0,9 & 0,8 & 0,9 & & & $*$ & 1,0 & 0,9 & 1,0 & & & $*$ & 0,9 & 0,9 & 0,9 \\
5 & & & & $*$ & 0,9 & 1,0 & & & & $*$ & 0,9 & 1,0 & & & & $*$ & 0,9 & 1,0 \\
6 & & & & & $*$ & 0,9 & & & & & $*$ & 0,9 & & & & & $*$ & 0,9 \\
9 & & & & & & $*$ & & & & & & $*$ & & & & & & $*$ \\
\hline
\end{tabular}

As avaliações de equivalência da versão traduzida demonstraram que houve equivalência semântica em $94,2 \%$ das questões, equivalência idiomática em $94,3 \%$ dos itens e $86,6 \%$ de equivalência cultural. Destaca-se a proporção de itens sobre os quais os juízes ficaram indecisos no aspecto cultural, 9,7\%.

Após a devolução do material, o grupo de especialistas reuniu-se para consenso. Durante a reunião, não houve dificuldades entre os juízes para o acordo sobre termos/expressões mais adequadas.

$\mathrm{Na}$ aplicação do pré-teste, obteve-se percentual de compreensão acima de $90 \%$ em todos os itens do instrumento. Como os participantes não tiveram dúvidas quanto às questões apresentadas, concluiu-se que o instrumento estava adequado para ser utilizado posteriormente. Dessa forma, a versão pré-final testada originou a versão final de igual teor, apresentada no final do texto.

\section{DISCUSSÃO}

A adaptação transcultural é um processo que requer o cumprimento de duas etapas claramente distintas: tradução e ajuste cultural do instrumento e sua validação para uso em outro cenário. O processo formal de adaptação transcultural tem a finalidade de avaliar e assegurar, com rigor, a equivalência entre o método no idioma original e sua versão traduzida. Não existe consenso sobre a melhor metodologia para traduzir e adaptar culturalmente um instrumento, no entanto, a escolha adequada permite a inclusão de variáveis específicas próprias da cultura e a adoção de uma linguagem clara, simples e de fácil acesso para a população.

A primeira fase da tradução originou duas traduções, uma com o sentido mais literal das palavras e a outra com o sentido contido nos termos. A reunião de pesquisadores para gerar a versão síntese foi importante para definir, entre as duas traduções, quais termos ofereciam mais clareza na interpretação contextual e que estavam mais adequados em relação ao instrumento original. Nesse sentido, o grupo optou por manter as traduções mais próximas do sentido original das palavras, uma vez que essa versão seria retrotraduzida.

A ausência de diferenças de sentido entre as duas retrotraduções e o instrumento original demonstrou semelhança de significado e conceito entre as versões, o que representou a boa qualidade das traduções realizadas.

A participação do grupo de pesquisadores nas fases de tradução e retrotradução foi importante para melhor ajuste do instrumento, uma vez que todos conheciam a versão original, as traduções, a síntese e as retrotraduções e puderam enriquecer as discussões.

No comitê de juízes, a participação de profissionais com diferentes formações e com experiência em pesquisa e assistência contribuiu para a equivalência entre o instrumento traduzido e o original.

A obtenção de consenso pelo grupo de especialistas, por meio de um processo reflexivo, indicou o esforço coletivo na busca por um objetivo comum, neste caso, a melhor qualidade da versão brasileira do método INTERMED.

As interferências dos especialistas deram-se no sentido de identificar os termos ou expressões que mais se adequariam à prática clínica nas diferentes profissões que devem manusear o instrumento. Por isso, foram eliminados itens considerados irrelevantes, ambíguos ou inadequados, substituindo-os por outros 
que garantissem a compreensão do instrumento, porém, mantendo o conceito dos itens.

O processo de construção do consenso requer disponibilidade de tempo, comprometimento e flexibilidade do grupo, pois cada membro deve estar aberto a discutir determinado tema em busca de uma definição que seja aceita como comum.

Na aplicação do pré-teste, o fato de os participantes não apresentarem dúvidas em relação às questões do instrumento indicou que o rigor metodológico empregado neste estudo possibilitou o desenvolvimento de um instrumento com qualidade de tradução e adaptação transcultural, com potencial para ser incorporado no sistema de saúde brasileiro como uma ferramenta que contribui para a integralidade do cuidado.

A disponibilidade dos autores que desenvolveram o método INTERMED e o apoio e atenção dados pela pesquisadora que promoveu o treinamento da equipe foram fatores que contribuíram para um desfecho consistente do estudo.

A metodologia empregada neste estudo foi considerada adequada, pois permitiu a inclusão de aspectos específicos da cultura brasileira e a adoção de uma linguagem clara, simples e de fácil acesso aos profissionais e pacientes.

Neste contexto, concluiu-se que o método INTERMED está adequadamente traduzido e adaptado para a realidade brasileira, pois envolveu aspectos específicos da cultura brasileira e a adoção de uma linguagem clara, simples e de fácil acesso aos profissionais e pacientes. Futuramente, essa ferramenta poderá facilitar a atuação da equipe interprofissional nos diversos níveis de atenção à saúde no contexto brasileiro.

\section{VERSÃO BRASILEIRA DO MÉTODO INTERMED}

\subsection{As questões direcionadoras [1-17] do INTERMED - entrevista}

\section{Introdução}

Conforme combinado, nós teremos esta entrevista visando entender melhor o que suas queixas atuais ou doença significam para você e o que é necessário para melhor controlar sua situação. Agora que nós sabemos sobre sua situação clínica, eu gostaria de ter melhor ideia de que tipo de pessoa você é e como você está lidando com seus problemas clínicos; essas informações ajudarão a organizar o cuidado, adaptado às suas necessidades individuais específicas. Durante a entrevista, vários tópicos serão abordados. Pode ser que haja certas questões, as quais você realmente gostaria de refletir um pouco mais. Para poder elaborar um plano de tratamento apropriado, é necessário, na nossa primeira conversa, ter/ criar visão geral dos problemas. Quando necessário, podemos focar essas questões na próxima fase. Você entende e concorda ou tem alguma dúvida? (Considere se o paciente é capaz de ser entrevistado).

1. Eu vou lhe contar o que eu sei sobre a razão de seu encaminhamento/ admissão e seu estado físico atual. Você deve me corrigir quando eu estiver errado [gravidade dos sintomas/ comprometimento; desafio diagnóstico/ terapêutico; cronicidade].

2. Agora eu gostaria de saber como você se sente fisicamente. Sua condição física tem impacto na sua atividade de vida diária? [Gravidade dos sintomas/ comprometimento].

3. Agora que você me informou como se sente fisicamente, eu gostaria de ter mais alguma informação a respeito de suas doenças físicas e tratamentos nos últimos cinco anos [cronicidade].

4. Os médicos tiveram alguma dificuldade em esclarecer um diagnóstico com as queixas/ doenças que você teve nos últimos cinco anos? Essas queixas não foram solucionadas? Atualmente, essas queixas estão sendo investigadas? [dilema no diagnóstico].

5. Quem tem sido os profissionais - médicos, psicólogos, enfermeiros ou assistentes sociais - que estão cuidando de você? Eles trabalham todos na mesma instituição e há coordenação para os atendimentos? [Organização do cuidado].

6. Existe comunicação mútua entre os profissionais que cuidam de você para discutir e ajustar seu tratamento? [Coordenação do cuidado].

7. Houve conflitos com médicos durante os últimos cinco anos, os quais te causaram má impressão, que podem interferir na sua confiança em médicos? [Experiência do tratamento].

8. Agora, eu gostaria de saber se você tem um bom sistema de saúde/ plano de saúde. Você já teve 
problemas com seu sistema de saúde/ plano de saúde? A distância das instituições onde você é tratado é apropriada ou você perdeu consultas devido à distância?

9. Até onde é de meu conhecimento, você pode ter uma formação cultural diferente. Os profissionais que cuidam de você levam isso em consideração? (O senhor tem algum costume/ hábito diferente que lhe é importante e que os profissionais de saúde não estão respeitando? Há problemas de comunicação devido a problemas de linguagem?) [Acesso ao cuidado].

10. Agora eu gostaria de mudar de assunto e lhe perguntar sobre o modo como você vive. Você tem um trabalho atualmente? Qual nível de escolaridade você alcançou? Você se formou? [Problemas relacionados ao trabalho e lazer].

11. Você é uma pessoa que consegue ter lazer? O que você faz para ter alguma distração? Você tem passatempos? [Problemas relacionados ao trabalho e lazer].

12. Você pode me contar como você vive atualmente? E no caso de doença ou deficiência, há alguém com quem você possa contar? [Condições no domicílio; rede de apoio social precária].

13. Agora eu gostaria de saber como você é. No geral, você é uma pessoa calma e estável? Você é alguém que consegue ter bom relacionamento com outras pessoas ou há conflitos às vezes? [Situação social; barreiras de enfrentamento].

14. Eu gostaria de lhe perguntar sobre sua dependência de tabaco e bebida e a relação destes com os seus problemas atuais. Você usa analgésico? Você às vezes se preocupa em usá-los em excesso? [Barreiras de enfrentamento].

15. Como você lida com situações difíceis? Estas seriam uma razão para usar álcool, tabaco ou drogas? Você é propenso a adiar decisões? Isso o levaria a falar demais ou ficar em silêncio? [Barreiras de enfrentamento].

16. Agora eu gostaria de saber como você se sentiu emocionalmente durante a última semana. Eu quero dizer tenso, ansioso, desanimado ou esquecido? [Sintomas psiquiátricos].

17. Você já consultou um psiquiatra alguma vez na sua vida ou houve períodos em que você esteve ansioso, deprimido ou confuso? [Disfunção psiquiátrica].

18. Finalmente, eu gostaria de saber como você segue as recomendações do seu médico. Você é uma pessoa que geralmente faz o que os médicos recomendam? [Resistência ao tratamento].

Agora, chegando ao final da entrevista, eu gostaria de enfatizar que você forneceu informações muito úteis. Vou elaborá-las e discuti-las com a equipe. Nós podemos discuti-las durante nossa próxima consulta. Eu finalmente gostaria de saber como você se sentiu nesta entrevista. Você acha que essas informações serão úteis para tratá-lo bem ou há informações importantes que faltaram? Você acha que não foi adequado fazer essas perguntas a você? Obrigada por sua paciência e disposição em fornecer informações. Se você quiser, eu resumirei os principais pontos levantados.

\section{As variáveis e seus pontos clínicos de apoio}

\section{BIOLÓGICO}

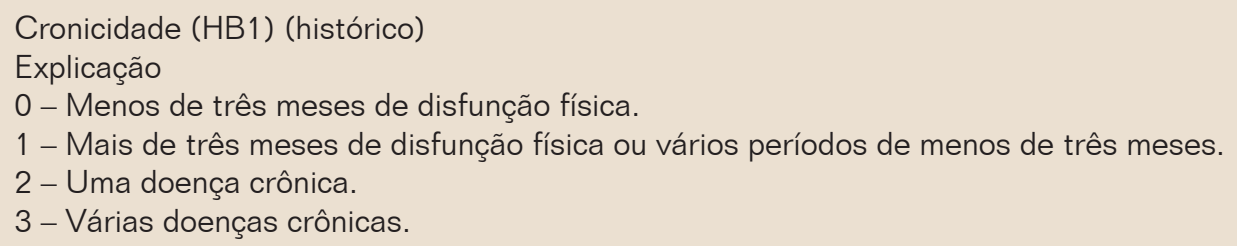

Dilema no diagnóstico (HB2) (histórico)

Explicação

0 - Sem períodos de complexidade diagnóstica.

1 - Diagnóstico e etiologia foram rapidamente esclarecidos.

2 - Dilema no diagnóstico resolvido, mas somente com esforço considerável para o diagnóstico.

3 - Dilema no diagnóstico não resolvido, apesar de esforços consideráveis para o diagnóstico. 
Gravidade dos sintomas/ comprometimento (CB1) (estado atual)

Explicação

0 - Sem sintomas ou sintomas reversíveis sem esforços médicos intensivos.

1 - Sintomas leves, mas significativos, que não interferem na funcionalidade atual.

2 - Sintomas moderados a graves, que interferem na funcionalidade atual.

3 - Sintomas graves que levam à incapacidade de realizar quaisquer atividades funcionais.

Desafio diagnóstico/ terapêutico (CB2) (estado atual)

Explicação

0 - Diagnósticos claros e/ou tratamento não complicado.

1 - Diagnósticos diferenciais claros e/ou diagnóstico esperado com tratamentos definidos.

2 - Dificuldade para diagnosticar a causa/origem física e tratá-la da forma esperada.

3 - Dificuldade de diagnosticar ou tratar outros problemas além de causas físicas interferindo no diagnóstico e no processo terapêutico.

Complicações e ameaça à vida (VB) (vulnerabilidades)

Explicação

? - Desconhecidas.

0 - Nenhum risco de limitações nas atividades da vida diária.

1 - Risco leve de limitações nas atividades da vida diária.

2 - Risco moderado de limitações permanentes e/ou significativas nas atividades da vida diária.

3 - Risco elevado de complicações físicas com sérios déficits funcionais permanentes e/ou morte.

\section{PSICOLÓGICO}

Barreiras de enfrentamento (HP1) (histórico)

Explicação

0 - Capacidade de manejar o estresse, tal como pela procura de apoio ou passatempos.

1 - Habilidades restritas de enfrentamento, tais como necessidade de controle, negação da doença ou irritabilidade.

2 - Habilidades insuficientes de enfrentamento, tais como queixas não pertinentes ou abuso de substâncias, porém sem sérios impactos na condição clínica, saúde mental ou situação social.

3 - Habilidades mínimas de enfrentamento, manifestadas por comportamentos destrutivos, tais como dependência de substâncias, doença psiquiátrica, automutilação ou tentativa de suicídio.

Disfunção psiquiátrica (HP2) (histórico)

Explicação

0 - Nenhuma disfunção psiquiátrica.

1 - Disfunção psiquiátrica sem efeitos claros na funcionalidade diária.

2 - Disfunção psiquiátrica com efeitos claros na funcionalidade diária.

3 - Hospitalização(ões) psiquiátrica(s) e/ou efeitos permanentes na funcionalidade diária.

Resistência ao tratamento (CP1) (estado atual)

Explicação

0 - Interessado em receber tratamento e disposto a cooperar ativamente.

1 - Alguma ambivalência, apesar de disposto a cooperar com o tratamento.

2 - Resistência considerável, tal como não adesão com hostilidade ou indiferença em relação aos profissionais de saúde e/ou tratamentos.

3 - Resistência ativa ao cuidado médico.

Sintomas psiquiátricos (CP2) (estado atual)

Explicação

0 - Sem sintomas psiquiátricos.

1 - Sintomas psiquiátricos leves, tal como dificuldade de concentração ou tensão.

2 - Sintomas psiquiátricos moderados, tais como ansiedade, depressão ou comprometimento cognitivo leve.

3 - Sintomas psiquiátricos graves e/ou distúrbios comportamentais, tais como violência, dano de autoagressividade, delirium, psicose ou mania. 
Ameaça à saúde mental (VP) (vulnerabilidades)

Explicação

0 - Sem risco de transtorno psiquiátrico.

1 - Risco leve de sintomas psiquiátricos, tais como estresse, ansiedade, tristeza, abuso de substância ou transtorno cognitivo; risco leve de resistência ao tratamento (ambivalência).

2 - Risco moderado de transtorno psiquiátrico, necessitando de cuidado psiquiátrico; risco moderado de resistência ao tratamento.

3 - Risco grave de transtorno psiquiátrico, necessitando de visitas frequentes ao serviço de emergência e/ou admissões hospitalares; risco de recusa ao tratamento devido a transtornos psiquiátricos sérios.

\section{SOCIAL}

Problemas relacionados ao trabalho e lazer (HS1) (histórico)

Explicação

0 - Trabalho/ ocupação (incluindo serviço doméstico, aposentadoria, estudos) e tem atividades de lazer.

1 - Trabalho/ ocupação (incluindo serviço doméstico, aposentadoria, estudos) e sem atividades de lazer.

2 - Atualmente desempregado e pelo menos seis meses com atividades de lazer.

3 - Atualmente desempregado e pelo menos seis meses sem atividades de lazer.

Situação social (HS2) (histórico)

Explicação

0 - Sem ruptura social.

1 - Dificuldade de interação social leve.

2 - Dificuldade de interação social moderada, tal como incapacidade de iniciar ou manter relações sociais.

3 - Dificuldade de interação social grave, tal como envolvimento em relações sociais conflitivas ou isolamento social.

\section{Condições no domicílio (CS1) (estado atual)}

Explicação

0 - Domicílio estável; totalmente capaz de viver independentemente.

1 - Domicílio estável com ajuda de outros, por exemplo, família, cuidador domiciliar ou institucional.

2 - Domicílio instável, por exemplo, sem apoio em casa ou vivendo em um abrigo; é necessária mudança da situação de vida atual.

3 - Sem domicílio atual satisfatório, por exemplo, moradia transitória ou ambiente perigoso; é necessária mudança imediata.

Rede de apoio social precária (CS2) (estado atual)

Explicação

0 - Suporte prontamente disponível de familiares, amigos e/ou conhecidos, tais como colegas de trabalho, em todos os momentos.

1 - Suporte disponível da família, amigos e/ou conhecidos, tais como colegas de trabalho, porém inconstante.

2 - Suporte limitado da família, amigos e/ou conhecidos, tais como colegas de trabalho.

3 - Sem qualquer suporte da família, amigos e/ou conhecidos, tais como colegas de trabalho.

Vulnerabilidade social (VS) (vulnerabilidades)

Explicações

0 - Sem risco de mudanças na situação de vida; suporte social e integração adequados.

1 - Sem risco de mudanças na situação de vida, mas são necessários melhor suporte social e integração, por exemplo, assistência domiciliária.

2 - Risco de admissão temporária ou permanente em instituição/ institucionalização no futuro previsível.

3 - Necessidade imediata de admissão temporária ou permanente em instituição agora.

\section{SISTEMA DE SAÚDE}

Acesso ao cuidado (HHS1) (histórico)

Explicação 
0 - Acesso adequado ao cuidado.

1 - Alguma limitação no acesso ao cuidado devido a problemas do sistema de saúde/ plano de saúde, razões geográficas, linguagem ou barreiras culturais.

2 - Dificuldades no acesso ao cuidado devido a problemas do sistema de saúde/ plano de saúde, razões geográficas, linguagem ou barreiras culturais.

3 - Sem acesso adequado ao cuidado devido a problemas do sistema de saúde/ plano de saúde, razões geográficas, linguagem ou barreiras culturais.

\section{Experiência do tratamento (HHS2) (histórico) \\ Explicação \\ 0 - Sem problemas com profissionais de saúde. \\ 1 - Experiência negativa com profissionais de saúde (sua ou de parentes).}

2 - Pedidos de segunda opinião ou mudança de médicos mais de uma vez; múltiplos profissionais; problema em manter profissional(is) estável(eis) e/ou de preferência.

3 - Repetidos conflitos com médicos, visitas frequentes ao serviço de emergência ou hospitalizações involuntárias; forçado a ficar com profissional indesejável devido a custo, opções de rede de profissionais ou outras razões.

Organização do cuidado (CHS1) (estado atual)

Explicação

0 - Somente atenção primária em saúde.

1 - Serviços especializados no cuidado geral da saúde ou saúde mental/ cuidado ao transtorno do uso de substâncias.

2 - Ambos, cuidado geral da saúde e serviços de cuidado de saúde mental/ transtorno do uso de substâncias.

3 - Hospitalização ou transferência do paciente, que se qualifica em cuidado ambulatorial no nível secundário.

Coordenação do cuidado (CHS2) (estado atual)

Explicação

0 - Comunicação completa com o profissional e boa coordenação do cuidado.

1 - Comunicação limitada com o profissional e coordenação do cuidado; médico da atenção primária coordena os serviços médicos e de saúde mental/transtorno do uso de substâncias.

2 - Comunicação precária e coordenação do cuidado entre os profissionais; sem médico da atenção primária de rotina.

3 - Nenhuma comunicação e coordenação do cuidado entre os profissionais; serviço de emergência utilizado para atender às necessidades de saúde não emergenciais.

Impedimentos do sistema de saúde/ plano de saúde (VHS) (vulnerabilidades)

Explicação

? - Desconhecidos.

0 - Sem risco de impedimentos para coordenar cuidado físico e de saúde mental/ transtorno do uso de substâncias.

1 - Risco leve de impedimentos ao cuidado, por exemplo, restrições do sistema de saúde/ plano de saúde, acesso distante ao serviço, comunicação limitada com os profissionais e/ou coordenação do cuidado.

2 - Risco moderado de impedimentos ao cuidado, por exemplo, potencial perda do sistema de saúde/ plano de saúde, profissionais inconsistentes, barreiras de comunicação.

3 - Risco elevado de impedimentos ao cuidado, por exemplo, pouco ou nenhum acesso ao sistema de saúde/ plano de saúde, resistência à comunicação e coordenação entre os profissionais.

Isso leva à seguinte classificação (Quadro 5): 
Quadro 5: Domínios e variáveis do INTERMED. São Paulo, 2012

\begin{tabular}{|c|c|c|c|c|c|c|}
\hline Domínios & \multicolumn{2}{|r|}{ História } & \multicolumn{2}{|r|}{ Estado atual } & \multicolumn{2}{|c|}{ Vulnerabilidade } \\
\hline \multirow[b]{2}{*}{ Biológico } & HB1 & $\begin{array}{l}\text { Cronicidade } \\
\text { (0) (1) (2) (3) }\end{array}$ & CB1 & $\begin{array}{l}\text { Gravidade sintomas } \\
\text { (0) (1) (2) (3) }\end{array}$ & \multirow[b]{2}{*}{ VB } & \multirow{2}{*}{$\begin{array}{l}\text { Complicações e } \\
\text { ameaça à vida } \\
(0)(1)(2)(3)(?)\end{array}$} \\
\hline & HB2 & $\begin{array}{l}\text { Dilema diagnóstico } \\
(0)(1)(2)(3)\end{array}$ & CB2 & $\begin{array}{l}\text { Desafio diagnóstico/ } \\
\text { Terapêutico } \\
\text { (0) (1) (2) (3) }\end{array}$ & & \\
\hline \multirow{2}{*}{ Psicológico } & HP1 & $\begin{array}{l}\text { Barreiras enfrentamento } \\
\text { (0) (1) (2) (3) }\end{array}$ & CP1 & $\begin{array}{l}\text { Resistência ao tratamento } \\
\text { (0) (1) (2) (3) }\end{array}$ & \multirow{2}{*}{ VP } & \multirow{2}{*}{$\begin{array}{l}\text { Ameaça à } \\
\text { Saúde mental } \\
(0)(1)(2)(3)\end{array}$} \\
\hline & HP2 & $\begin{array}{l}\text { Disfunção psiquiátrica } \\
(0)(1)(2)(3)\end{array}$ & $\mathrm{CP} 2$ & $\begin{array}{l}\text { Sintomas psiquiátricos } \\
(0)(1)(2)(3)\end{array}$ & & \\
\hline \multirow[b]{2}{*}{ Social } & HS1 & $\begin{array}{l}\text { Problema trabalho/lazer } \\
\text { (0) (1) (2) (3) }\end{array}$ & CS1 & $\begin{array}{l}\text { Condições no domicílio } \\
\text { (0) (1) (2) (3) }\end{array}$ & \multirow[b]{2}{*}{ VS } & \multirow{2}{*}{$\begin{array}{l}\text { Vulnerabilidade } \\
\text { social } \\
\text { (0) (1) (2) (3) }\end{array}$} \\
\hline & HS2 & $\begin{array}{l}\text { Situação social } \\
\text { (0) (1) (2) (3) }\end{array}$ & CS2 & $\begin{array}{l}\text { Rede de apoio social } \\
(0)(1)(2)(3)\end{array}$ & & \\
\hline \multirow{2}{*}{$\begin{array}{l}\text { Sistema de } \\
\text { saúde }\end{array}$} & HHS1 & $\begin{array}{l}\text { Acesso ao cuidado } \\
\text { (0) (1) (2) (3) }\end{array}$ & $\mathrm{CHS} 1$ & $\begin{array}{l}\text { Organização do cuidado } \\
(0)(1)(2)(3)\end{array}$ & \multirow{2}{*}{ VHS } & \multirow{2}{*}{$\begin{array}{l}\text { Impedimentos do } \\
\text { sistema/ } \\
\text { Plano de saúde } \\
\text { (0) (1) (2) (3) (?) }\end{array}$} \\
\hline & HHS2 & $\begin{array}{l}\text { Experiência tratamento } \\
(0)(1)(2)(3)\end{array}$ & $\mathrm{CHS} 2$ & $\begin{array}{l}\text { Coordenação do cuidado } \\
\text { (0) (1) (2) (3) }\end{array}$ & & \\
\hline score & & & & & & \\
\hline
\end{tabular}

\section{REFERÊNCIAS}

BANDEIRA, M.; CALZAVARA, M. G. P.; VARELLA, A. A. B. Escala de sobrecarga dos familiares de pacientes psiquiátricos: adaptação transcultural para o Brasil (FBIS-BR). J Bras Psiquiatr, v. 54, n. 3, p. 206-214, 2005.

BEATON, D. E.; BOMBARDIER, C.; GUILLEMIN, F.; FERRAZ, M. B. et al. Guidelines for the process of crosscultural adaptation of self-report measures. Spine, v. 25, n. 24, p. 3186-3191, 2000.

CARVALHAL, A. Are women a different group of HIV-infected individuals? Arch Womens Ment Health, v. 13, p. $181-183,2010$.

ENGEL, G. L. The need for a new medical model: a challenge to biomedicine. Science, v. 196, n. 4286, p. 129-136, Apr 1977.

GUILLEMIN, F. Cross-cultural adaptation and validation of health status measures. Scand J Rheumatol, v. 24, p. 61-63, 1995.

HUYSE, F. J. et al. INTERMED: a method to assess health service needs. I. Development and reliability. Gen Hosp Psychiatry, v. 21, n. 1, p. 39-48, 1999.

RAMOS, F. R. S. et al. Trabalho, educação e política em seus nexos na produção bibliográfica sobre o cuidado. Texto Contexto Enfermagem, Florianópolis, v. 18, n. 2, p. 361-368, abr/jun. 2009.

REICHENHEIM, M. E.; MORAES, C. L. Operacionalização de adaptação transcultural de instrumentos de aferição usados em epidemiologia. Rev Saude Publica, v. 41, n. 4, p. 665-673, ago. 2007.

WALTZ, C. F.; STRICKLAND, O. L.; LENZ, E. R. Measurement in nursing research. Philadhelphia: F. A. Davis Company, 1991. 